\title{
Emotions as indeterminate justifiers
}

\author{
András Szigeti ${ }^{1}[0$
}

Received: 9 February 2021 / Accepted: 16 July 2021 / Published online: 6 August 2021

(c) The Author(s) 2021

\begin{abstract}
Sentimentalists believe that values are crucially dependent on emotions. Epistemic sentimentalists subscribe to what I call the final-court-of-appeal view: emotional experience is ultimately necessary and can be sufficient for the justification of evaluative beliefs. This paper rejects this view defending a moderate version of rationalism that steers clear of the excesses of both "Stoic" rationalism and epistemic sentimentalism. We should grant that emotions play a significant epistemic role in justifying evaluations. At the same time, evaluative justification is not uniquely or especially dependent on emotions. The anti-sentimentalist argument developed in this paper is based on the indeterminacy thesis. The thesis states that the evaluative properties picked out by our emotional responses are too indeterminate to play a central role in our evaluative practices. I argue that while the indeterminacy thesis undermines the final-court-of-appeal view it supports the claim that emotional responses can provide prima facie justification for evaluative beliefs.
\end{abstract}

Keywords Indeterminacy $\cdot$ Emotions $\cdot$ Sentimentalism $\cdot$ Sentimentalism · Justification · Value

\section{Introduction}

Sentimentalism is the view that values are dependent on or are inherently linked to human emotions. The main focus of this paper will be the epistemic aspect of the relationship between value and emotion. More specifically, the paper asks whether and to what extent emotions can provide us with justification for evaluative beliefs.

\section{This article belongs to the topical collection "Indeterminacy and Underdetermination", edited by} Mark Bowker and Maria Baghramian.

András Szigeti

andras.szigeti@liu.se

1 Linköping University/Lund University, Linköping/Lund, Sweden 
According to one popular approach, evaluative knowledge is grounded in emotions. I will refer to this theory as epistemic sentimentalism. The position is most starkly opposed to "Stoic" rationalism that portrays all emotions as tendentiously biasing our evaluations. ${ }^{1}$ On this account, emotions can never provide knowledge and never even positively contribute to acquiring knowledge either. Epistemic sentimentalism and "Stoic" rationalism are, however, not our only options. My ultimate aim in this paper is to muster additional support for a more moderate version of rationalism that seeks to steer clear of the excesses of both extreme positions. We should grant that emotions play a significant epistemic role in justifying evaluations. At the same time, evaluative justification is not uniquely or especially dependent on emotions. There are other routes to obtaining knowledge of value.

Moderate rationalists are prepared to grant that emotions can play a positive and sui generis epistemic role. As will be seen, some rationalists, while willing to ascribe such a role to emotions, deny that emotions can justify or rationalize evaluative beliefs. On that account, emotions are epistemic motivators but not sources of justifying reasons (see esp. Brady, 2013). The kind of moderate rationalism defended in this paper will take an even more conciliatory approach. I want to argue that emotions can justify evaluative beliefs in the sense that one can point to one's relevant emotional experience as one legitimate reason for accepting an evaluative belief.

The most radical form of epistemic sentimentalism does claim that only emotions can justify evaluative beliefs because the only reason one can have for holding an evaluative belief is an emotional experience. ${ }^{2}$ However, it is not necessary to combine epistemic sentimentalism with explanatory or psychological sentimentalism of this kind. The epistemic sentimentalist can admit that we can also have various non-emotion-based reasons for accepting an evaluative belief-we may rely on testimony, for example. What the epistemic sentimentalist will claim, however, is that the final court of appeal for justifying an evaluative claim must be a relevant emotional experience. This means that an emotional response is ultimately necessary for the justification of an evaluative belief and also that the emotional response in itself can be sufficient for such justification (Sect. 2).

This paper rejects the final-court-of-appeal view. When we examine how emotions latch onto evaluative properties, we will find that there must be other, emotion-independent routes to obtaining knowledge of value. The crucial argument here will be what I call the indeterminacy thesis (Sect. 3). Nevertheless, as noted, I recommend a more conciliatory approach than rival versions of moderate rationalism

\footnotetext{
1 The scare quotes signal that ascribing this view to the Stoics, albeit not unusual, may be historically inaccurate (see Perler, 2011, espp. 120-122).

2 This could be because every evaluative belief is constituted or necessarily caused by an emotional experience. See, for example, Haidt (2012). Perceptualism, i.e., the view that emotions are perceptions of value properties, entails radical epistemic sentimentalism as well if it is thought that the only way to access evaluative properties is by perceiving through our emotional responses. This seems to be the position expressed in the following quote: "If one has never been moved or affected by the determinate ways in which things are beautiful or charming or erotic or banal or sublime or horrific or appealing, then one is ignorant of the relevant determinate values" (Johnston, 2001, p. 183).
} 
insofar as I concede that emotions can provide justificatory reasons (Sect. 4.1) and reject some objections to this claim (Sect. 4.2). I then go on to show that the justificatory role of emotions is limited because they are neither necessary nor sufficient for the justification of evaluative beliefs, except for a relatively unimportant subcategory of them (Sect. 4.3).

\section{Emotions and evaluative properties}

Epistemic sentimentalists subscribe to the final-court-of-appeal view: emotional experience is ultimately necessary and can be sufficient for the justification of evaluative beliefs. Note that it is compatible with the final-court-of-appeal view to say that in any given case the mere recognition of the aptness of an emotional experience can do the justificatory work. For example, one may just be too tired or depressed to feel excitement, joy or anger, but can nevertheless recognize that some such emotional response would be fitting. Still, even in such cases appeal to someone's actual emotional experience is necessary: the justification of the evaluative belief now at $t_{n}$ relies on emotional responses (of one's own or that of others) to a previous situation at $\mathrm{t}_{\mathrm{n}-1}$ (or previous situations at $\mathrm{t}_{\mathrm{n}-\mathrm{x}}$ ). In short, the justification of any evaluative belief will appeal to some emotional experience at least when the justification is fully spelled out.

Before examining this view, however, it is worth asking what ulterior grounds one may have for adopting it. One reason for adopting epistemic sentimentalism is that it is entailed by metaphysical sentimentalism, as we will see in a minute. Still, one can embrace epistemic sentimentalism on independent grounds too, without being committed to metaphysical sentimentalism. While epistemic sentimentalism without metaphysical sentimentalism is a coherent position, it is much less straightforward than a combination of the two kinds of sentimentalism because, as will be explained below, metaphysical sentimentalism actually provides an explanation of why epistemic sentimentalism could be true, whereas on the second approach it remains something of a mystery why emotions should have a privileged connection to value (see Kauppinen, 2014, p. 56). In this section, I will first trace the first route to epistemic sentimentalism, and then briefly reconstruct the second. In any case, the objections to be made against epistemic sentimentalism are meant to apply to epistemic sentimentalism with or without metaphysical sentimentalism.

\subsection{Metaphysical sentimentalism}

What is an emotion about, or what is it directed towards? On the one hand, fear can be directed towards all kinds of things such as dogs, death, and the destruction of the planet due to global warming. Anger can be directed, among countless other things, towards laptops, losses, and Liam for behaving so awkwardly last evening. These are not only different objects, but also different types of objects (i.e., some are facts, others are physical objects or persons). Now, what is common to things we fear? That 
they are fearsome. And what is common to everything we are angry about? That they are irritating or vexatious or "angersome". 3

The evaluative property common to all the things we fear is being fearsome. The evaluative property common to all the things we are angry about is being irritating/ vexatious/ "angersome". ${ }^{4}$ I will refer to evaluative properties picked out by emotional responses as sentimental evaluative properties (SEPs) adding the subscript SEP to the labels of the relevant properties, e.g., fearsome ${ }_{\text {SEP. }}$ Correspondingly, I will add NEP to evaluative properties not picked out by our emotional responses, e.g., blameworthy ${ }_{\mathrm{NEP}}$

The primary concern of metaphysical sentimentalism is ontological. It is about the nature of value properties or about what value properties are. Specifically, metaphysical sentimentalism holds that the concepts of evaluative properties playing a central part in morality and elsewhere are dependent on emotional responses (see Kauppinen, 2014). Emotional responses do not only pick out evaluative properties (SEPs) in the way just sketched, but also fix the extension of the concept of each evaluative property. In virtue of this ontological dependence relation, emotions are to be understood as constitutive of value. ${ }^{5}$

It might seem that this approach is uninformative. This would be the case if all one could say about a type of emotional response (e.g., fear) is that it picks out a certain evaluative property (the fearsome $\mathrm{SEP}){ }^{6}$ However, to be fair to sentimentalists, we can do much better than that. There are characteristic behavioral patterns associated with each distinct kind of emotion such as guilt or fear. Each type of emotion is associated with certain typical action tendencies (e.g., fear normally motivates avoidance and retreat). Further, for each type of emotion we can also make out typical eliciting conditions (e.g., fear is normally triggered by what is perceived to be a threatening situation or action). In addition, the characterization of these patterns can be significantly enhanced by examining the host of available biological, sociological and psychological facts about each emotion as regards their adaptivity, neurophysiology, socialization, and cultural variability. Finally, we can also learn more about the phenomenology of these emotions by introspection.

\footnotetext{
${ }^{3}$ In some dialects of English, the term is synonymous with "irritating" and not "irritable".

${ }^{4}$ It is often said that emotions present or represent such evaluative properties, e.g., my fear (re)presents the dog as fearsome. The representationalist view is not entirely unproblematic (see Echeverri, 2017 for discussion and Mulligan, 2009 for objections), but I believe nothing in the following depends on whether one accepts the view or not. I have therefore opted for the non-committal formulation that emotions "pick out" evaluative properties. It should also be clear that this view of emotions as evaluative appraisals (of SEPs) does not entail judgmentalism (see for example Elster, 1999; Döring, 2010; Döring, 2015), i.e., the view that emotions are moral or evaluative judgments (Nussbaum 2001).

${ }^{5}$ See, for example, Prinz $(2007,175)$ : “... rightness and wrongness depend, metaphysically, on the sentiments people have". Also, Mulligan, (1998, p. 161): "For to be valuable is just for certain emotional responses to be appropriate.".

${ }^{6}$ There is an additional worry here about circularity. It might appear that ultimately all we can say about what is common to all instantiations of a given evaluative property is that they are picked out by a certain emotion, and ultimately all we can say about that emotion is that it picks out that evaluative property. Wiggins, (1987) and McDowell (1998) may well be right, however, that such circularity is a strength not a weakness.
} 
In other words, by studying a response-pattern and the associated type of experience (e.g., observationally, the pattern of guilt-responses, and introspectively, the experience of feeling guilt) we can circumscribe the evaluative property ${ }_{S E P}$ that response-pattern homes in on, that is, define the concept of the property ${ }_{\text {SEP }}{ }^{7}$ Apart from the specific focus on emotional responses, this is in line with the procedure we are recommended to follow for response-dependent concepts in general such as concepts of secondary qualities. It has been argued that for such concepts the response or experience is definitionally prior in the sense that we cannot understand the property without invoking the response, while the converse is not true: we can have a good grasp of the response without having a concept of the property. For example, we cannot understand what it is to be green without pointing to green perceptions or to how it is for things to look green to people. However, arguably, we do not have to grasp what it is to be green to have a grasp of what it is to have green perceptions or what it is for something to look green to people (Peacocke, 1984).

Nor would it be right to object here that by prioritizing the response we cannot define the concept of the property because on this approach anything we happen to react to with the given response will be an instantiation of the property. For example, so the complaint goes, anything that triggers fear will have to be counted on this approach as an instantiation of the fearsome ${ }_{\mathrm{SEP}}$. In response, we can observe that people make certain presuppositions about the intrapersonal and interpersonal stability of their responses allowing them to conclude on certain occasions that despite appearances the response-dependent property is not instantiated, and that the response was only triggered because the conditions were unusual or because the subject of the response was radically different from ordinary subjects. Such responses will then be discounted (Pettit, 1990, p. 12; Pettit, 1991, pp. 600-1). For example, in some cases something may have not appeared green to someone because that person is red-green colorblind. Since people systematically discount a variety of such abnormal cases as being due to perturbing influences (also known as defeat$\mathrm{ers}^{8}$ ), we can establish a response-pattern which is not only descriptive, but also normative, i.e., a pattern that functions as a rule to detect perceptual error and illusion. The best interpretation of that rule will give us in turn the concept of the property that the response tracks.

The same procedure can be used to arrive at the concepts of evaluative properties emotional responses track. We do not think that everything that triggers fear is fearsome $_{\text {SEP. }}$. We are aware that a fear reaction may have been triggered only because the conditions were unusual or because the subject of the response was radically different from ordinary subjects. The conditions are unusual when one's emotions do not function normally, say, due to the influence of medication or a psychological condition such as depression, or when special circumstances obtain as in the case of seemingly hard-wired, recalcitrant emotional reactions such as the fear of heights

\footnotetext{
7 Wiggins, for example, makes this connection explicit here: “...elucidate the concept of value by displaying it in its actual involvement with the sentiments. One would not... have sufficiently elucidated what value is without that detour." (Wiggins 1987, p. 189).

8 See Tappolet (2000) for a detailed discussion of defeaters.
} 
or snakes (D’Arms \& Jacobson, 2003). Since people systematically discount such abnormal cases, the response-pattern for an emotion can serve as a normative rule that helps to detect error and illusion. If that is the case, we can use the best interpretation of that rule to obtain the concept of the evaluative property a given emotion tracks.

In the case of emotions, the concept of the evaluative property is often designated as the emotion's core relational theme. ${ }^{9}$ The core relational theme of fear is danger or threat ${ }^{10}$ because the best interpretation of our fear responses-which interpretation also takes into account the discounted cases of fear reactions due to perturbing conditions - shows that people expect fear reactions to track dangers and threats. In similar ways, we can obtain a gloss of the core relational theme of sadness as "irrevocable loss" (Prinz \& Nichols, 2010, p. 119), and of envy as "portray[ing] a rival as having a desirable possession that one lacks, and cast[ing] this circumstance in a specific negative light." (D’Arms \& Jacobson, 2000a, p. 66).

Finally, once the core relational theme of the emotion is established it can be used as a criterion of the fittingness of emotional responses. A given emotional reaction is fitting if the object of the emotion instantiates the relevant sentimental evaluative property. Fear, for example, is fitting if the (material) object of fear really is fearsome $_{\text {SEP }}$ (D'Arms \& Jacobson, 2000b). ${ }^{11}$

\subsection{Metaphysical sentimentalism and epistemic sentimentalism}

Metaphysical sentimentalism has epistemic implications. D'Arms and Jacobson highlight these implications in the following way (2010, 611, italics mine): We are not claiming that [emotional] sensibilities are guaranteed to get matters right, or even that they are statistically more likely to be correct than are sincere evaluative beliefs. Our point is rather that they have internal connections to sentimental values which theoretical reflection does not. This fact renders such reflection prone to forms of error and confusion from which sensibilities are immune.

But what exactly are these implications? And why should they follow? As regards the epistemic justification of evaluative beliefs, two important points follow from the dependence of sentimental evaluative properties (SEPs) on emotional responses: a necessity-claim and a sufficiency-claim.

The first implication is that appealing to emotional responses is necessary for the justification of evaluative beliefs. The justification of the belief, for example, that something is dangerous or threatening must ultimately refer to one or another subject's fear. The subject of the emotional experience need not be identical with the subject of the belief-the latter can, for example, rely on the testimony of the former. Still, a full justification of the evaluative belief must invoke the fear responses of people somewhere upstream. On the final-court-of-appeal view, a complete

\footnotetext{
9 Or as the formal object of the emotion (Teroni 2007).

10 Below, I will say more on a potential difference between the two.

11 For a careful neo-sentimentalist analysis of the funny as the property of being "amusement-worthy", see Shoemaker (2017a).
} 
justification of any given evaluative belief necessarily invokes an emotional response even if not necessarily an occurrent one. ${ }^{12}$

This means that the justification of evaluative beliefs depends on emotions in much the same way as the justification of perceptual beliefs depends on perceptions. My reason here and now for believing that the mailbox is red can be that somebody tells me that it is red, but at the end of the day somebody must have seen that the mailbox is red. Likewise, my reason here and now for believing that eating meat is wrong or cruel may be that other people convinced me. Still, somebody upstream must have felt morally outraged by the practice.

The second implication is that the emotional response can be sufficient for the justification of evaluative beliefs. As we have seen, the metaphysical dependence of the property on the response means that the relevant kind of response will fix the extension of the property's concept. If so, then it is impossible that the relevant emotional responses are always mistaken. If fear, for example, fixes the dangerous or the threatening, then at least sometimes our fear reactions must pick out what is indeed dangerous or the threatening. ${ }^{13}$ But if that is correct, then it must be true too that the relevant response can be sufficient to justify the evaluative belief that the pertaining evaluative property is instantiated.

This is because if the relevant response cannot always be mistaken, then in some cases it must be the fitting response, i.e., be a response to the instantiated evaluative property. And if that is the case, then the response itself can provide sufficient reason to justify the evaluative belief that the relevant evaluative property is indeed instantiated. Thus, my fear can be sufficient to justify my belief that the dog is dangerous or threatening. I could be wrong in any given case since I may have failed to notice the presence of a defeater, e.g., I may be unaware of my chronic phobia of a certain kind of dog. But in general, if one has no reason to believe that a defeater is present, ${ }^{14}$ then one can take

\footnotetext{
$\overline{12}$ Here is an illustrative example suggested by David Shoemaker (see, 2017b). Imagine two professional comedians going through jokes for a show they are planning. They might say, "yes, that's funny", "no, that one is not" without laughing or displaying any sign of amusement. Even here of course the comedians' justification for their evaluative belief appeals to the emotional response of amusement (their own and/or those of their audience), just not an occurrent one. Similarly, an atheistic anthropologist might train herself to become a good judge of what counts as sacred in the culture she is studying even though she never herself feels awe. But her judgments cannot be fully justified without appealing to cases in which members of that community do feel awe.

13 This is in fact generally true for all response-dependent properties. If a certain response fixes a property, then it is impossible for every relevant response to that property to be erroneous. Pervasive error and ignorance are impossible (see esp. Pettit, 1991, p. 592). If, for example, green perceptions (i.e., things looking green) fix what is for something to be green, then it is impossible that all green perceptions should be mistaken. If thoroughgoing error or ignorance were possible, how could green perceptions fix the property of being green?

14 There is a difference between the requirement that one should have no reason to believe that defeaters are present and the requirement that one should have reason to believe that there are no defeaters present. The latter, strongly internalist requirement is defended by Elgin 2008, the former, more externalist approach by Tappolet (2000), Hookway (2008), and many others (see esp. Brady (2013), 76n80 for discussion).
} 
the response to provide a sufficient reason for accepting the given evaluative belief. ${ }^{15}$

The upshot of this is that commitment to metaphysical sentimentalism entails commitment to epistemic sentimentalism, i.e., the view that emotions are the final court of appeal for the justification of evaluative beliefs. ${ }^{16}$ As noted, there is no entailment in the other direction: one can in principle be an epistemic sentimentalist without being a metaphysical sentimentalist. If emotions are more reliably correlated with evaluative properties than other kinds of responses to these evaluative properties, then the final-court-of-appeal view will follow. If, however, evaluative properties do not depend for their existence on emotional responses, then it will be hard to explain why of all possible ways of accessing evaluative properties emotions should be the most reliable means of doing so. Fortunately, in what remains, we can set this issue aside as the objections to epistemic sentimentalism made below apply equally to versions of this position which are not committed to metaphysical sentimentalism.

\footnotetext{
15 Again, a straightforward analogy can be drawn with perceptual appearances and corresponding perceptual beliefs: it must be true that something appearing green can be a sufficient justification for the belief that something is green since if looking green fixes what it is to be green, then in some cases green perceptions are indeed fitting, i.e., the green perception is indeed of something green. And so, as long as one has no reason to believe that a defeater is present one can take the green perception to be a sufficient justification that what one perceives as green is indeed green.

${ }^{16}$ This implication is recognized, among others, by Pettit (1991), Elgin (2008) and D'Arms \& Jacobson (2010). Somewhat surprisingly, Brady (2013, see es pp. 114-5) argues that metaphysical sentimentalism entails the falsity of epistemic sentimentalism. It could be interesting to briefly rehearse his argument here. On Brady's view, combining metaphysical sentimentalism (MS) and epistemic sentimentalism (ES) would commit us to the implausible claim that emotional experiences could justify themselves. He thinks this would follow because for epistemic sentimentalists the fact that I have an emotional experience can give me some reason to believe that an evaluative property is instantiated. However, for metaphysical sentimentalists an evaluative property is instantiated iff the emotional reaction is a fitting reaction to it. So, if we accepted both MS and ES, we would have to say that the emotional reaction is a reason to believe that evaluative property is instantiated (from ES), but if indeed the evaluative property is instantiated, then we have reason to have the emotional reaction (from MS). And so, the emotional reaction would justify itself. For illustration, consider Brady's example, one's fear of a charging of bull: if ES, then fear is a reason judge the bull dangerous, but if MS, then the bull's being dangerous just is to have reason to fear it. So, if ES + MS, then from the fact that we are afraid of the bull we could conclude that it is fitting to be afraid of the bull. The experience of fear thus seems to justify itself. Brady thinks this is an unpalatable conclusion, and so we should reject ES if we accept MS. For reasons discussed at the end of this section (and in the references just cited), I think that, on the contrary, ES actually follows from MS. Two further points are worth mentioning here. First, as Mitchell (2017) shows, it is not obvious that emotional reactions cannot be self-justifying in this way. That this is possible is at least implied by Wiggins (1987) as well. Second, even if Brady were right that the idea of self-justifying emotional experience was confused, this would not be a problem for the account defended here. This is because, on my account, emotional responses and evaluative judgments track different properties (SEPs and NEPs, respectively). In short, I deny MS for most evaluative properties, namely all NEPs (which is just as well since if I am right that MSES, then rejecting ES entails rejecting MS too, see also the following footnote). I develop this reply to Brady's worries about epistemic sentimentalism in more detail elsewhere (Szigeti, 2021).
} 
The question now is what evaluative properties are picked out by our emotional responses and how important these properties are in our evaluative practices. This is the issue I turn to in the next section.

\section{3. The indeterminacy thesis}

There are some important concerns about the actual significance of evaluative properties picked out by emotional responses. I want to mention two, related difficulties. I will argue that the implication of these is that epistemic role of emotions is limited. ${ }^{17}$

François Schroeter (2006) argued that even if the sentimentalist is successful in unequivocally identifying evaluative properties picked out by emotions (SEPs) these evaluative properties will not be of great interest. I have said above that people expect fear reactions to track dangers and threats. However, so Schroeter's objection goes, this is an illicit equivocation which the sentimentalist should not be allowed to help herself to. The fearsome $_{\mathrm{SEP}}$ is what is adequately perceived as threatening, which may or may not in fact be dangerous ${ }_{\mathrm{NEP}}$. Plausibly, all big hairy spiders and slithering snakes are threatening, and

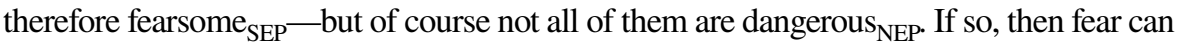

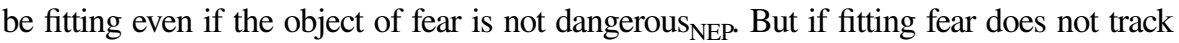
the dangerous, then fitting fear cannot settle whether something is dangerous or not. And since studying fear cannot help us any further, we have to settle by means of non-affective criteria whether the property of being dangerous is instantiated or not. Furthermore, it is argued that this point generalizes to other evaluative properties as well.

Moreover, unfortunately, the evaluative property we are truly interested in, the one we want our evaluations to track and the one we want to guide our actions-also because this is often essential to our survival-is not the fearsome ${ }_{\mathrm{SEP}}$ but the dangerous ${ }_{\mathrm{NEP}}$. This conclusion generalizes for many evaluative properties including several central properties targeted by our moral evaluations. The evaluative property ${ }_{S E P}$ tracked by (fitting) resentment (or anger) will not be extensionally equivalent with moral blameworthiness ${ }_{\mathrm{NEP}}$. Therefore, we cannot define moral blameworthiness by focusing on resentment (or anger). In general, the sentimentalist analysis can only define the concept of evaluative properties which are picked out by our emotional responses (SEPs), but these properties are of limited interest because they only at best partially overlap with those properties our evaluative practices are mostly and centrally concerned with. ${ }^{18}$

\footnotetext{
17 Since metaphysical sentimentalism entails epistemic sentimentalism, the following objections against epistemic sentimentalism imply (by modus tollens) that metaphysical sentimentalism is false as well. I hasten to add that rejecting sentimentalism is not tantamount to rejecting the response-dependence of evaluative properties. The criticism is only directed against privileging emotional responses.

18 I believe but cannot argue here that this applies to the central evaluative properties of aesthetics as well. For example, the admiration we feel for a work of art picks out admirability SEP. However, $_{\text {, }}$ admirability $_{\text {SEP }}$ is arguably only a quite indeterminate property that serves as a rough-and-ready indicator of aesthetic value. As such, feelings of admiration can aid but should not conclusively settle our aesthetic judgments. In order to establish non-sentimental evaluative properties of a work of art (e.g., complexity $_{\mathrm{NEP}}$, originality $\mathrm{NEP}_{\text {, social and historical significance }}$ NEP ), we study works of art, i.e., we engage in aesthetic criticism, hermeneutical and exegetic debates, and other reflective forms of aesthetic reception. Of course, a lot more would have to be said to properly engage with sentimentalism in aesthetics, which has been hugely influential. Hopefully, however, this sketch already gives some idea of how one might attempt to extend the indeterminacy thesis to that domain. I thank an anonymous reviewer
} 
Perhaps the most forceful sentimentalist response to this objection is to question the non-sentimentalist's portrayal of NEPs. The sentimentalist may point out that no independent characterization of these supposedly non-sentimental evaluative properties is possible-independent, that is, from emotional responses. For example, it might look like we can characterize the dangerous without appealing to fear. However, all attempts at such characterization will founder on easily produced counterexamples. At the end of the day, the only thing that holds together the otherwise disparate set of dangerous things as a class is that they all merit fear. ${ }^{19}$

An inherent weakness of this sentimentalist response is that its support for sentimentalism is mainly negative. First, even if sentimentalists are right to reject this or that response-independent theory they owe us an explanation why the responsedependent theory should be cashed out in terms of emotions rather than some other type(s) of non-emotional response. And second, it is not so clear that we are worse off with a response-independent theory that is susceptible to some counterexamples than with an emotion-dependent theory taciturn about what exactly the norms of fittingness are for a given emotion.

Setting these dialectical points aside ${ }^{20}$ there are may be some deeper reasons for not being satisfied with the sentimentalist approach. The principal problem is that whether or not one accepts the sentimentalist response just discussed sentimental evaluative properties will remain indeterminate and this will significantly restrict their usefulness in our evaluative practices.

I will refer to this problem as the indeterminacy thesis. The thesis states that the evaluative properties picked out by our emotional responses (SEPs) are insufficiently determinate to play a central role in our evaluative practices. Before providing arguments in support of the thesis, let me illustrate the problem using the case of blameworthiness. How to define the concept of blameworthiness is the subject of an intense and complex philosophical debate. Does blameworthiness require the ability to do otherwise? Are there situations in which all available actions are blameworthy? Can actions making marginal or imperceptible contributions to collectivelybrought-about, overdetermined harms be blameworthy? These are just some of the fundamental questions discussed in connection with blame. Now, the emotion standardly associated with blame is resentment (Strawson, 1974; Wallace, 1994, etc.). However, it is hard to see how scrutinizing patterns of when we feel and express resentment, could ever settle such controversies because the evaluative property resentment picks out- "the resentment-worthy ${ }_{\text {SEP }}$ - - is just too indeterminate. Nor

\footnotetext{
Footnote 18 (continued)

for raising the important issue of the generalizability of the indeterminacy thesis to aesthetic and other normative properties.

19 This is how D'Arms and Jacobson argue against Schroeter (2016). See the blog entry: http://peaso up.typepad.com/peasoup/2014/02/featured-philosophers-darms-and-jacobson.html. Schoemaker (2017a) pursues the same strategy in his analysis of the funny and the blameworthy as SEPs.

20 There is a further problem, which I will mostly ignore here, about how well sentimentalist analyses work for thin evaluative properties such as moral wrongness/rightness or moral goodness/badness.
} 
are these marginal issues which only concern peripheral, exotic, or "fuzzy" cases. ${ }^{21}$ These questions address the very core of the concept of what it is to be blameworthy (see also Szigeti, 2015). So, to clarify, the general point is not that there is no fact of the matter as to whether SEPs apply. Nor is the point that SEPs could not be applied in a systematic way. In fact, as I will argue below, SEPs do have a systematic relationship to NEPs. Rather, what the indeterminacy thesis claims is that, even when SEPs are in fact instantiated, the fact that they are instantiated will not settle the kind of normative ethical (and aesthetic) issues or quandaries we face when we engage in ethical (or aesthetic) deliberation or debates, and this is because these SEPs are too uninformative and inconclusive to settle such deliberations and debates.

The situation can be to some extent compared to, say, red-green colorblindness (protanopia) or the difficulties of Japanese native speakers encounter in distinguishing the English phonemes $/ \mathrm{l} /$ and $/ \mathrm{r} /$. It is reported that people suffering from protanopia see neither green nor red but rather a murky, indeterminate greyish color. ${ }^{22}$ Japanese speakers do not confuse / $/$ and /r/ but hear a single consonant $/ \mathrm{r} /$ instead of both. The property $y_{S E P}$ our resentment responses latch onto are like that murky color or that Japanese consonant. So, feelings of resentment pick out an evaluative property that is indeterminate with regard to the finer distinctions mentioned above which are relevant to the concept of blameworthiness-in the same way as the colorblind person's perceptions are indeterminate with regard to the difference between red and green or untrained Japanese speakers' auditory sensations do not discriminate between $/ \mathrm{l} /$ and $/ \mathrm{r} /$.

Now, why exactly should the indeterminacy thesis constitute a problem for the sentimentalist? In fact, David Shoemaker (2017a) argues that it does not constitute a problem-either for a neo-sentimentalist analysis of moral responsibility or for a neo-sentimentalist approach to value in general. For example, Shoemaker argues, the fact that resentment ${ }^{23}$ can be fitting both in cases where the agent could have done otherwise and where she could not have does not mean that being blameworthy could not be understood as being "resentment-worthy". Blameworthiness just turns out to be a more multifaceted property than we may have thought. If so, then the indeterminacy of resentment is a virtue rather than a vice.

In response I want to make three points not only to challenge Shoemaker's position but also in order to further clarify the indeterminacy thesis. So, first, once we admit such widely multifaceted properties (to which it can be appropriate to respond with a certain emotion), it is unclear how we will be able to establish a binding normative standard for any given emotional response type (e.g., resentment). Even if we can make sure that no defeaters are present, we will not be able to exercise effective normative criticism of our evaluations (not even those of our past and future selves).

\footnotetext{
${ }^{21}$ Resolving these indeterminacies would be important in order to differentiate various emotions from one another. It is often said, for example, that what distinguishes regret from guilt (or anger from resentment) is that only the latter entails a (self-)attribution of moral responsibility.

22 See here for some attempted visual representation of how the colorblind see the world: https://www. boredpanda.com/different-types-color-blindness-photos/

23 Shoemaker (2017a) treats anger roughly synonymously with resentment.
} 
On what grounds would we say that resentment, or any other emotion for that matter, is appropriate if we cannot point to a fairly cohesive property which that emotion picks out?

Some sentimentalists may not be overly disturbed by these relativistic implications. ${ }^{24}$ However, second, it is also unclear how we can make sure on this account that there are no defeaters present. In Sophie's Choice, ${ }^{25}$ for example, should we say that Sophie's guilt is fitting even though she could not have made a better choice, or should we say that it is not fitting since given her deep personal involvement in the situation her emotional sensibilities did not function properly? I do not see how the neo-sentimentalist can answer this question in a non-question-begging way, i.e., without engaging in a non-sentimentalist analysis of the evaluative property instantiated by Sophie's action. ${ }^{26}$

Third, and crucially, even setting these two difficulties aside, it is hard to see how this version of neo-sentimentalism can do justice to the ambitious epistemic claims made on behalf of emotions by sentimentalists. If the evaluative properties our emotional responses track are indeed as multifaceted as Shoemaker makes them out to be, then our emotional responses do not tell us much about the world. Shoemaker allows that the list of reasons rendering a given type of emotional response fitting will not only be wildly disjunctive but also contradictory. If so, then what can I deduce from consulting my emotions? Not much. The dog may really constitute a threat to me, or not, the resentment-worthy agent may have voluntarily harmed me or not, and so on. I will not know what the case is, even if my emotion is fitting. It also bears repeating that this applies not only to unusual or unfamiliar situations for which our emotional dispositions may indeed be not well prepared, but it is a common feature of everyday emotional experiences. The upshot is that whether or not Shoemaker's version of sentimentalism is metaphysically feasible it could not be used to establish the sentimentalists' claim that emotions play an important epistemic role in justifying evaluative beliefs. This point generalizes to many evaluative properties picked out by emotional responses.

Granted, the point may not generalize to all sentimental evaluative properties. That is, some SEPs may be sufficiently determinate to play a central role in certain evaluative practices. This could be the case when there is simply no non-sentimental evaluative property (NEP) that the practice could focus on because the only way the

\footnotetext{
${ }^{24}$ Prinz (2007), for example, is quite happy to embrace them.

25 Sophie's Choice (Greenspan, 1983) is a central example in the debate about the possibility of moral dilemmas, i.e., cases where no justified course of action is available. Sophie receives this offer: "choose between your two children, otherwise both will be killed". Sophie chooses one of her children and so only one child is killed. Many-both friends and foes of moral dilemmas-believe that analyzing Sophie's emotional response is the key to resolving this debate. Elsewhere, I reject this strategy (Szigeti, 2015) precisely on the grounds that emotional reactions are too indeterminate. There I also criticize the last-ditch suggestion that the indeterminateness of Sophie's emotional reaction would show that there is no fact of the matter as to what response by Sophie would be appropriate.

26 See Szigeti (2015). The point made above also implies that, despite Shoemaker's protestations to the contrary (see 2017a), his fitting response-dependence approach collapses into a dispositional responsedependence theory and struggles with the very problem he diagnoses for that theory (namely, how to offer a non-question-begging account of defeaters).
} 
property is accessible to us is by means of the emotional response. For example, the funny $_{\text {SEP }}$ may be such a property. ${ }^{27}$ Perhaps it is true that the best we can do when considering whether something is funny is to consult our corresponding emotional reactions of amusement and hilarity and make sure no defeaters are present. Certain forms of visceral disgust and shock in the face of brutality and transgression, or on the positive side, varieties of elation and joy might conceivably belong to this category as well. ${ }^{28}$ In such cases (where no determinate NEP underlies the normative practice), it might not even matter that quite different and even contradictory considerations can render these emotional responses fitting. However, note that the emotional reactions which are sensitive to such SEPs will not say much about world.

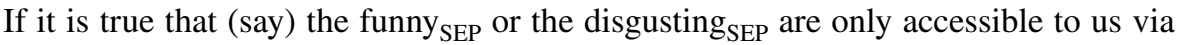
amusement and disgust respectively, then these reactions will not be terribly informative about things "out there" because, as it seems to be conceded by the sentimentalist, these reactions can be fitting in response to a wide variety of cases (some of which may even be contradictory).

In any case, I do not exclude the possibility that there are other such evaluative properties and corresponding emotional reactions for which no corresponding, more determinate NEPs can be found. How many such SEPs there are in fact, and whether they are more rampant when we move closer to the aesthetic and/or gustatory realms of evaluation must be left to the piecemeal analysis of the relevant normative practices. However, even if there are more such SEPs (for which no more determinate NEPs can be made out), the indeterminacy thesis would pose a serious challenge to sentimentalism if indeed there are sufficient number of NEPs playing a central role in normative ethics (and aesthetics), which is the case as I argue above.

It bears repeating that none of this should be taken to entail that the evaluative properties picked out by emotions would be wholly undefinable or completely useless, ${ }^{29}$ but it does imply that the generality and lack of precision of the concepts of such properties significantly restrict the importance of these properties in our evaluative practices. Most importantly, this finding casts doubt on the central ambition of the sentimentalist program, which is to provide emotion-based definitions of the key evaluative and moral properties in our everyday normative practices. No doubt the evaluative properties picked out by our emotions can adequately serve some of our theoretical and practical purposes. In some cases, all that matters is whether an action is resentment-worthy $y_{\mathrm{SEP}}$ or an object fearsome ${ }_{\mathrm{SEP}}$, and we do not care whether the action is blameworthy ${ }_{\mathrm{NEP}}$ or the object dangerous ${ }_{\mathrm{NEP}}$. However, it seems to follow from the indeterminacy thesis that when we want to rely on more precise

\footnotetext{
27 As argued by Shoemaker (2017a).

28 This could be one way of interpreting the moral dumbfounding experiment by Haidt (2012), although of course the experiment was originally supposed to underwrite a much more radically sentimentalist position (see footnote 2). I thank an anonymous reviewer for pressing this issue.

29 Specifically, this claim is not intended to call into question the many uses of emotions discussed in the literature including such more narrowly epistemic functions as the ability of emotions to pick up saliences, direct attention, identify reasons for action, and give rise to unique phenomenal experiences (see Elgin (2008), Goldie (2008), Hookway (2008), Brady (2013). Nor does the above view exclude the possibility of adjusting and re-calibrating our emotional responses.
} 
evaluative properties, we cannot invoke our emotions and have to rely on non-affective criteria.

Note also that the indeterminacy of sentimental evaluative properties is not due to the possible presence of defeaters. ${ }^{30}$ The point is that emotions were not "set up" to track the relatively sophisticated but important distinctions the feasibility of many of our evaluative beliefs depend on. Therefore, even when perturbing influences are eliminated and conditions are favourable or ideal, sentimental evaluative properties will not be coextensive with non-sentimental evaluative properties. Even when conditions are optimal the pattern of our fear/resentment responses will pick out the fearsome ${ }_{\mathrm{SEP}}$ or the resentmentworthy ${ }_{\mathrm{SEP}}$, not the dangerous ${ }_{\mathrm{NEP}}$ or the blameworthy ${ }_{\mathrm{NEP}}$. In short, even the best interpretation of these response-patterns will only give us the concept of the sentimental evaluative property (SEP), not the concept of the non-sentimental evaluative property (NEP). ${ }^{31}$

But what are the implications of the indeterminacy thesis regarding the epistemic role of emotions? This is the question I will consider in the next section arguing that while the indeterminacy thesis undermines the final-court-of-appeal view, it is not inconsistent with the claim that emotional responses can provide prima facie justification for evaluative beliefs.

\section{Circumscribing the justificatory role of emotions}

\subsection{The relationship between SEPs and NEPs}

It would considerably diminish the appeal of any form of rationalism if it implied that emotions could provide no justification for evaluative beliefs. It seems commonsensical that if I am afraid of that dog, I have some reason believe it is dangerous. If I feel guilty about what I have done, then my feeling gives me reason to believe that my action was blameworthy. It is epistemically virtuous in many cases not to disregard one's emotional responses when evaluating a situation or an action. We may encourage our children to treat the deliverances of their emotions with some caution, but it can hardly be good parenting to tell them to completely ignore their feelings. This view of the epistemic role of emotions is also supported by empirical research. For example, it has been found that the breakdown of basic emotional capacities due to neurophysiological damage is responsible for some people's inability to reason and deliberate normally (Damasio, 1994). ${ }^{32}$

\footnotetext{
${ }^{30}$ It is worth considering in this context Goldie's claim (2008) that emotions can systematically mislead our evaluative judgments. The possibility of systematic error implies that emotions can mislead even in the absence of defeaters. What the indeterminacy thesis does is to provide an explanation for the possibility of systemic error in the case of emotion-based evaluations.

31 So even ideal observers' emotional responses will fail to pick out important non-sentimental evaluative properties. For example, even an ideal observer's resentment will fail to track blameworthiness.

32 There are also pragmatic reasons for relying on our emotions as an epistemic resource. Briefly, emotions are special in terms of how they deliver information about value: emotional reactions are typically fast and spontaneous. So, in some cases, for example when time is short or there is a risk of cognitive overload, they can provide useful information which would otherwise be unavailable given the practical
} 
Fortunately, the indeterminacy thesis does not exclude assigning a justificatory status to emotional experiences. On the contrary, it is an advantage of the thesis that it allows us to articulate that role. Even if the fearsome ${ }_{\mathrm{SEP}}$ and the dangerous $\mathrm{NEP}_{\mathrm{N}}$ are not coextensive, the referents of the concepts of these properties do partially overlap. Even if patterns of resentment and guilt do not determinately fix the property of blameworthiness, many of the actions we resent or feel guilty about are indeed blameworthy. If so, then fear can at least to some extent justify the belief that something is dangerous, and resentment and guilt can at least to some justify the belief that an action is blameworthy. ${ }^{33}$

So even if the indeterminacy thesis is true, it presents no obstacle to systematizing the relationship between the fearsome and the dangerous or harmful, or between the sentimental evaluative property picked out by guilt/resentment and the blameworthy. In other words, we can make fairly good predictions about when the evaluative property picked out by the emotion will overlap with its relevant non-evaluative counterpart and when it will not. Empirical research can help to explain why such a systematic relationship in fact obtains. For example, plausible evolutionary accounts have been offered for why our emotions perform well in some situations and fail in others.

It is also worth noting that while ordinary participants in evaluative practices may not always be aware of or not care about such explanations, information about the systematic limitations of the deliverances of our emotions are in principle available to them as well. In fact, I would argue that a closer look at how and when we rely on our emotions manifest our awareness of such limitations. In some cases, we patently distrust our emotions. Sometimes this is because we suspect the presence of defeaters, but sometimes we seem to be aware of the systematic limitations of emotional experience. ${ }^{34}$

The upshot of this is that accepting the argument from indeterminacy does not commit one to denying that emotions can provide prima facie justificatory reasons

Footnote 32 (continued)

exigencies of the situation. I discuss the empirical literature on sui generis characteristics of emotions as an epistemic resource and their relationship to other forms of evaluation in Szigeti (2013).

33 It is also worth noting that emotions can serve as correctives of other emotions as in the case presented by Prinz (2007, pp 112-4) of the homophobe malgré soi ashamed by her instinctive homophobic repulsion. That such second-order emotions can play a corrective role can be granted but it is implausible that the only way we can correct our first-order emotional reactions is by means of such second-order emotions. Nor should it be expected that such second-order corrective emotions would always be present, or that even when they are present, they would be more reliable than first-order ones. It is therefore implausible to think that the indeterminacy of SEPs can in general be resolved by combining different emotional responses. So, while in the actual case discussed by Prinz shame may indeed override homophobic repulsion, this does not show that shame is less indeterminate than repulsion. I am grateful to two anonymous reviewers for raising these issues.

34 Among others, we tend to treat our emotional responses with caution when we find them to be recalcitrant, or partial, or indeterminate, or indiscriminate. Most people, for example, realize that just because flying makes them anxious flying is not dangerous (and if they still refrain from flying it is not because they think otherwise, but because they cannot cope with the anxiety). Simply put, most people seem to be aware, or can at least be made aware at least in some contexts and some of the time, that their emotions are a useful but fallible epistemic resource. For a fascinating discussion of cases from literature and real life when people seem to display such critical awareness (and also of cases when they do not), see Elster (1999). 
for adopting evaluative beliefs. As long as there is a systematic relationship between evaluative properties picked out by our emotions (SEPs) and other evaluative properties (NEPs), and as long as we have some awareness of there being such a relationship, which we do, emotional responses can play a part in justifying evaluative beliefs. ${ }^{35}$ Based on the considerations adduced in this section, it seems that there is such a relationship_one that empirical accounts can explain, and more importantly, one that ordinary participants in evaluative practices can be aware of. So, for example, as long as the fearsome ${ }_{\mathrm{SEP}}$ stands in a systematic relationship to the dangerous $_{\mathrm{NEP}}$ and we as ordinary practitioners have some awareness of this relationship, our fear responses can be a useful indicator of the dangerous, and so provide partial justification for our evaluation that something is dangerous.

\subsection{Can emotions justify at all?}

Some have nevertheless thought emotions cannot play any justificatory role, not even as a source of prima facie justificatory reasons. I will try to rebut some of these objections in this section.

Can the inveterate racist's feeling of indignation towards interracial marriages justify-even so much as prima facie justify — his belief that such marriages are morally wrong (Sinnott-Armstrong, 1991)? It is of course plausible to say that it cannot. However, the crucial point is that if his indignation does not provide any reason for his belief, it is not because indignation is an emotion. The inveterate racist could try to justify his belief that such marriages are morally wrong not by invoking his emotional reaction but based on another belief, say, his belief that racial purity is something to strive for. However, since that belief is unjustified as well, it cannot provide any justification for his belief that interracial marriages are wrong. In short, the problem with the inveterate racist's indignation as a source of justification is not that it is an emotion, but that it is an unjustified emotion. ${ }^{36}$

It might be said that the problem with relying on emotions as justifiers is that emotions are untrustworthy because they are contingently dependent on our subjective and cultural values and personal character (see Salmela, 2011). However, once again, this feature does not make reliance on emotions any more problematic than reliance on other epistemic resources. No matter what epistemic resource we turn to in order to justify our evaluative beliefs our justificatory reasons can be criticized for being contingent upon our subjective and cultural values and personal character (see esp. Sher, 2001). In fact, many would argue that even perceptual experiences

\footnotetext{
35 In fact, as long as there is a reliable and systematic connection between the evaluative properties our emotional responses pick out (SEPs) and non-sentimental evaluative properties (NEPs) externalists may not even require that one be aware of such a connection, and not even that it should be in principle accessible to one. I have nevertheless included that requirement to show that attributing a justificatory role to emotions does not presuppose externalism.

36 On justifying emotions, see Echeverri (2017). It is important to distinguish between the question whether an emotion is justified, on the one hand, and whether emotions can contribute to the justification of evaluative beliefs, on the other. That said, the second question depends to some extent on the first since only a justified emotion can itself justify an evaluative belief.
} 
are subject to the same contingencies due to the possibility of cognitive penetration (Vance, 2014). So, this is a problem not at all restricted to sentimentalism.

Still, is perhaps emotional justification particularly prone to this weakness given the inherently perspectival and subjective character of our emotions? As we have seen, emotional and perceptual experiences are often compared in terms of their potential to justify evaluative and perceptual beliefs, respectively. ${ }^{37}$ However, it could be said that perceptual experiences, despite themselves being somewhat influenced by subjective perspective and cognitive penetration, are actually much better suited to provide justification for beliefs. This is because the stability of standards for assessing the reliability of perceptual appearances is ensured by objective facts about human beings (e.g., we can measure the reliability of our sense organs), while the standards for emotional experiences lack such support and are therefore unstable. ${ }^{38}$ For example, it appears to us in the Müller-Lyer illusion that the lines are of unequal length and so we have a prima facie reason to believe that this is the case. Naturally, in this case we have available to us a way to conclusively defeat the prima facie reason for believing that the lines are unequal: we can simply measure them.

What gives rise to this worry, however, is a naïve distinction between fact and value. On the one hand, this distinction ignores the essential response-dependence of what are traditional called secondary qualities, and it forecloses the possibility of arguing that response-dependence is global, i.e., that all our concepts "are contaminated with subjectivity in a manner that is thought to be distinctive of secondary quality concepts" (Pettit, 1991, p. 588). Since at least ascriptions of secondary qualities (but, if Pettit is right, perhaps the ascription of all properties falling under the concepts of human beings) are subject-involving, the norms of such ascriptions will be shaped by human sensibilities and interests. In that respect at least, they will not be categorically different from emotion-backed ascriptions of evaluative properties.

On the other hand, this argument also assumes that as long as emotions are dependent on a personal perspective or one's character, we are barred from realizing intrapersonally and interpersonally stable standards by which to assess the reliability of the deliverances of emotions. But this too seems mistaken. While the prima facie justification for the perceptual belief that the lines are unequal in the Müller-Lyer illusion can indeed be cancelled by measuring the length of the lines, this does not establish that justification of perceptual beliefs by perceptual experiences is epistemically superior to justification of evaluative beliefs by emotional experiences. To the extent measurements themselves are understood to be statements of stable similarity relations among perceptions, perceptual justification remains dependent on other perceptions even when the justification of perceptual beliefs is furnished by measuring the objects of perception.

\footnotetext{
37 See Brady, (2013); Brogaard \& Chudnoff, (2016); Dietz, (2017; Milona, (2016), etc. But cf. Mulligan, (2009); Tappolet (2000); Vance, (2014), and others for a range of important observations as to why the relevance of the comparison may actually be quite limited. Note also that many of these authors' objections to the perceptual analogy remain relevant even if one does not accept perceptualism about emotions.

38 A similar objection is considered and rejected (on somewhat different grounds) by Elgin (2008).
} 
Let us briefly retrace our steps. Thus far I have argued, first, that emotions provide access to distinct kinds of evaluative properties. Second, I offered an account of the systematic nature of the relationship between evaluative properties picked out by emotions and non-sentimental evaluative properties (SEPs and NEPs), and third, based on this account I tried to explain how emotions can provide prima facie justification for evaluative beliefs. At the same time, I also reject epistemic sentimentalism: emotions are neither necessary nor sufficient for the justification of (most of our) evaluative beliefs. I move on to defending this claim in the next section.

\subsection{Can emotions be the final-court-of-appeal for justifying evaluative beliefs?}

The rejection of the sentimentalist's final-court-of-appeal view follows from the indeterminacy thesis. If the thesis is correct, then sentimental evaluative properties are very general, unspecific evaluative properties which are not sufficiently determinate to support all but a special subset of our evaluative beliefs, namely beliefs that the very sentimental evaluative property is being instantiated (i.e., that " $\mathrm{X}$ is fearsome SEP" or "Y is shameful SEP ").

As noted above, most of our evaluative beliefs are not of this sort. A great number of our evaluative beliefs seek to make more specific and determinate assertions and refer to non-sentimental evaluative properties. Consider almost any issue currently discussed in normative ethics - many of which are of great significance in our everyday lives as well: Is it blameworthy to contribute to collectively-brought-about, overdetermined harms? Is it unfair for A to exploit B even if there is mutual consent and mutual gain? If abortion is permissible, then is it also permissible for a wouldbe father to renounce his paternal responsibilities and rights before the child is born? Are there situations in which any course of action is morally unjustifiable? ${ }^{39}$

I have argued that our emotional reactions to such situations offer some guidance-both for the theoretician thinking about such cases and the practitioner facing hard choices. There is a partial overlap between SEPs and NEPs, emotional responses can be used to infer that a non-sentimental evaluative property is being instantiated. My feeling guilt about driving an SUV or eating meat gives me some reason to believe that I deserve blame for my pertaining choices because there is a partial overlap between things that are guiltworthy ${ }_{S E P}$ and those that are blameworthy $_{\mathrm{NEP}}$. Likewise, because there is a partial overlap between things that are resentmentworthy $_{\mathrm{SEP}}$ and things that are unjust ${ }_{\mathrm{NEP}}$, the workers' resentment of the sweatshop owner's employment policies gives them (and a third-party's indignation gives her) some reason to believe that the workforce is indeed treated unjustly. And so on. A friend's indignation about the father who chooses to walk away and the absence of similar feelings about a woman who chooses abortion gives that friend some reason to believe that the permissibility of abortion and elective abandonment by fathers are not to be treated on par. In Sophie's Choice, Sophie's guilt (or is it

\footnotetext{
39 Again, my view is that these points regarding the epistemic limitations-but also the epistemic usefulness of emotional reactions - carry over relatively unproblematically to the aesthetic domain for the reasons briefly sketched in footnote 18 .
} 
regret?) about choosing one of her children to die gives her some reason to believe that her action was morally problematic. In sum, our emotional reactions to such situations can provide prima facie justificatory reasons because there are relatively stable and to some extent systematic correlations between sentimental evaluative properties and non-sentimental evaluative properties, and ordinary participants can be and often are aware of these correlations. ${ }^{40}$

But can emotional reactions suffice for the justification of most evaluative beliefs and are they necessary for such justification? Take the sufficiency claim first. The problem is that we cannot without further ado move from the fearsome ${ }_{\mathrm{SEP}}$ to the dangerous $_{\mathrm{NEP}}$ because, as we have seen, the fearsome ${ }_{\mathrm{SEP}}$ and the dangerous $\mathrm{NEP}_{\mathrm{N}}$ are not extensionally equivalent. Since fear, even when fitting, fails to completely track the dangerous our fear responses will be of limited use when we want to establish whether something is dangerous or not. It is true that we sometimes have little else to base our assessment of some situation and what actions it calls for than our initial emotional reaction. That, however, does not mean that emotional reaction can be sufficient to justify an all-things-considered assessment. To illustrate the problem, consider this toy example. By and large more expensive products tend to be of higher quality. In short, price is a defeasible and more or less reliable indicator of a product's worth. Now sometimes we sometimes have little else to base our assessment than the price. Wanting to have the best and being in a rush, we grab the most expensive item from the shelf (if we can afford it). But does this show that price in itself gives us sufficient grounds to make an inference to the product's quality? Surely, not.

So, what emotions reveal to their subjects is at best the presence of the evaluative property picked out by that emotion (SEPs). Even if the subject has access to those evaluative properties thanks to the emotional experience, in most cases she will want to know more. She will want to know not only whether something is fearsome SEP

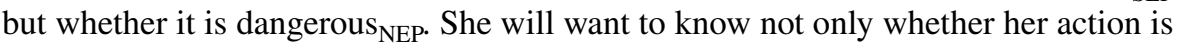

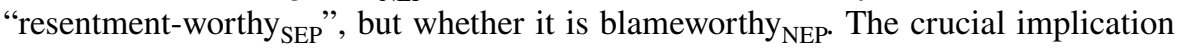
of the indeterminacy thesis is that to establish whether the "resentment-worthy" is blameworthy she will have to mobilize non-affective epistemic resources as well. The emotional reaction itself will not reveal whether in the given case the sentimental evaluative property and the non-sentimental evaluative property overlap, or not. ${ }^{41}$

\footnotetext{
40 As noted, externalists think we can do without the awareness-condition.

41 Hopefully, this clarifies that the anti-sentimentalist concerns raised here are different from (and partly critical of) those raised by other rationalists. As already noted, one anti-sentimentalist argument is that taking emotional experiences as justificatory reasons presupposes that these experiences can be selfjustifying. My argument, however, does not depend on accepting Mitchell's claim (2017) that (contra Brady, see 2013) emotional experiences can be self-justifying (although I do agree with Mitchell and Wiggins (1987) that the idea is by no means incoherent). The point is that on my view whether or not emotional experiences can be self-justifying (and more generally, whether or not there is some principled way to distinguish between justified and unjustified emotional experiences) emotional experiences track SEPs, not NEPs. SEPs may overlap with NEPs (sometimes the fearsome ${ }_{\mathrm{SEP}}$ is dangerous ${ }_{\mathrm{NEP}}$ ), but given the indeterminacy of SEPs this needs to be established by mobilizing additional epistemic resources, and so emotional experience cannot be sufficient to justify the belief that some NEP is instantiated.
} 
Again, it is good epistemic practice to treat one's emotions in this way and to be aware of these limitations of their epistemic role. It bears repeating that our epistemic responsibilities are not only to monitor the presence of defeaters, but also to consider the ever-present possibility of a mismatch between the sentimental properties our emotions pick out (SEPs) and non-sentimental evaluative properties (NEPs). If someone were to say, "that dog is dangerous (harmless) because I am afraid (not afraid) of it", then we would rightly balk at treating one's emotional reaction as providing a sufficient reason to accept that the dog is dangerous (harmless)-even when we have no reason to believe that defeaters are present (e.g., chronic dog phobia). As noted, there are more or less standard defeaters for moral emotions as well. Reliance on resentment or guilt requires that one is not stressed, emotionally unstable, etc. However, the point is that even when such defeaters are absent emotions can only provide limited information regarding the evaluation of the situation, e.g., whether an action is blameworthy ${ }_{\text {NEP. }}$ If someone were to say, "that joke I cracked yesterday was (not) offensive because I (don't) feel guilty about it”, we would think that whether or not one feels guilty about the joke can hardly settle conclusively whether it was offensive or not-even when conditions are favorable (or even ideal) and no perturbing influences on one's emotional dispositions seem to be present (e.g., the agent is not stressed, stricken by a neurotic guilt-complex, etc.).

Nor are emotions necessary for the justification of evaluative beliefs. It follows from the indeterminacy thesis that emotions latch onto a limited range of relatively indeterminate evaluative properties, namely NEPs. The overlap between NEPs and SEPs is at best partial (the fearworthy SEP $_{\text {is not always dangerous }}$ NEP, and conversely). Therefore, in many cases we have to be able to access SEPs by means other than our emotional reactions.

\section{Conclusion}

I have argued that emotional reactions are not the final court of appeal for evaluative beliefs. Epistemic subjects are not entitled to treating them as such and it is not good epistemic practice to do so. This follows from the indeterminacy thesis according to which emotional responses pick out sentimental evaluative properties that are too coarse-grained to provide answers to most of the questions our evaluative beliefs are concerned with. To answer those questions, rationalist strategies of reflection as well as intrapersonal and interpersonal deliberation will be necessary. Only by mobilizing these additional epistemic resources can we hope to gain access to those more fine-grained properties (NEPs).

I have also argued that emotions can provide prima facie justification for evaluative beliefs. This means that the emotional experience can be cited by its subject as one reason for holding that evaluative belief. This is not because emotions would be reducible evaluative judgments, but rather because there is a relatively systematic correlation between sentimental evaluative properties (SEPs) and non-sentimental evaluative properties (NEPs), and this correlation is accessible to ordinary participants in evaluative practices. Given this correlation, it is good epistemic practice to treat emotional reactions as providing prima facie reasons for evaluative beliefs. 
The position defended here steers a middle course between "Stoic" rationalism and epistemic sentimentalism. It also diverges from those moderate rationalists who think that the sui generis epistemic role of emotions is limited to motivating the search for reasons. It should also be noted that the argument in favor of this position has not been motivated by the worry that emotional evaluations would be too subjective. Finally, as mentioned above, it is not inconsistent with this position to maintain that evaluative properties are response-dependent. Many of the sentimentalist response-dependence accounts take it for granted that if evaluative properties are response-dependent, then they must be emotion-dependent. Going forward it may be worth exploring a more catholic response-dependence theory which makes evaluative properties metaphysically and epistemically dependent on a variety of human responses (potential candidates include desires, preferences, intuitions, and so on). Such a theory, which arguably also sits more comfortably with empirical data on the complexity of human cognition, could include emotions without privileging them. These conciliatory features should make rationalism more flexible and so more attractive even to those who may have thought it incompatible with an anthropocentric approach to value.

For reasons of space, the bearing of empirical research on the conceptual arguments made above could not be undertaken here. It is frequently said that one of the main comparative strengths of sentimentalism is its compatibility with naturalism broadly understood. Thus, it can be crucial to making rationalism more appealing to take steps towards demonstrating its empirical feasibility. It is therefore worth noting in closing that the version of moderate rationalism defended in this paper is not empirically implausible insofar as it is at least consistent with research on the evolutionary origins, psychology, and neurophysiology of emotions. While my arguments in this paper have been of conceptual nature, I think that there are a number of empirically informed models of the architecture underlying the characteristic role emotions play in justifying our evaluations. ${ }^{42,43}$

\section{Funding Open access funding provided by Lund University.}

Open Access This article is licensed under a Creative Commons Attribution 4.0 International License, which permits use, sharing, adaptation, distribution and reproduction in any medium or format, as long as you give appropriate credit to the original author(s) and the source, provide a link to the Creative Commons licence, and indicate if changes were made. The images or other third party material in this article are included in the article's Creative Commons licence, unless indicated otherwise in a credit line to the material. If material is not included in the article's Creative Commons licence and your intended use is not permitted by statutory regulation or exceeds the permitted use, you will need to obtain permission directly from the copyright holder. To view a copy of this licence, visit http://creativecommons.org/licen ses/by/4.0/.

\footnotetext{
${ }^{42}$ For two such models, see Sinnott-Armstrong et al. (2010) and Szigeti (2013).

43 I wish to thank especially Wlodek Rabinowicz, Paul Russell, David Shoemaker, and Fredrik Stjernberg as well as three anonymous referees of this journal for helpful comments and discussions on various versions of this paper. Further, I gratefully acknowledge the financial support of the Lund Gothenburg Responsibility Project (LGRP) funded by the Swedish Research Council.
} 


\section{References}

Brady, M. (2013). Emotional insight. Oxford University Press.

Brogaard, B., \& Chudnoff, E. (2016). Against emotional dogmatism. Philosophical. Issues, 26, 59-77.

D'Arms, J., \& Jacobson, D. (2000a). The moralistic fallacy: On the 'appropriateness' of emotions. Philosophy and Phenomenological Research, 61, 65-90.

D’Arms, J., \& Jacobson, D. (2000b). Sentiment and value. Ethics, 110, 722-748.

D'Arms, J., \& Jacobson, D. (2003). The significance of recalcitrant emotion (or, anti-quasijudgmentalism). In A. Hatzimoysis (Ed.), Philosophy and the emotions (pp. 127-146). Cambridge University Press.

D’Arms, J., \& Jacobson, D. (2010). Demystifying sensibilities: Sentimental values and the instability of affect. In P. Goldie (Ed.), The Oxford handbook of philosophy of emotion (pp. 585-613). Oxford University Press.

Damasio, A. R. (1994). Descartes' error. Picador.

Dietz, C. H. (2017). Reasons and factive emotions. Philosophical Studies, 175, 1681-1691.

Döring, S. A. (2015). What's wrong with recalcitrant emotions? From irrationality to challenge of agential identity. Dialectica, 69(3), 381-402.

Döring, S. A. (2010). Why be emotional? In P. Goldie (Ed.), The Oxford handbook of philosophy of emotion (pp. 283-301). Oxford University Press.

Echeverri, S. (2017). Emotional justification. Philosophy and Phenomenological Research, 98, 541-566.

Elgin, C. Z. (2008). Emotion and understanding. In: G. Brun, U. Doğuoğlu, U., \& D. Kuenzle (Eds.), Epistemology and emotions. Ashgate Publishing, pp. 33-50.

Elster, J. (1999). Alchemies of the mind: Rationality and the emotions. Cambridge University Press.

Goldie, P. (2008) Misleading emotions. In: G. Brun, U. Doğuoğlu, U, \& D. Kuenzle (Eds.), Epistemology and emotions (pp. 149-166). Ashgate Publishing, Uk.

Greenspan, P. S. (1983). Moral dilemmas and guilt. Philosophical Studies, 43, 117-125.

Haidt, J. (2012). The righteous mind, Pantheon.

Hookway, C. (2008). Epistemic immediacy, doubt and anxiety: On a role for affective states in epistemic evaluation. In: G. Brun, U. Doğuoğlu, U. \& D. Kuenzle (Eds.) Epistemology and emotions (pp. 51-66). Ashgate Publishing

Johnston, M. (2001). The authority of affect. Philosophy and Phenomenological Research, 63, 181-214.

Kauppinen, A. (2014). Moral sentimentalism. Stanford Encyclopedia of Philosophy.

McDowell, J. (1998). Projection and truth in ethics. In J. McDowell (Ed.), Mind, value, and reality, Harvard University Press (pp. 151-166)

Milona, M. (2016). Taking the perceptual analogy seriously. Ethical Theory and Moral Practice, 19, 897-915.

Mulligan, K. (1998). From appropriate emotions to values. The Monist, 84, 161-188.

Mulligan, K. (2009). Emotions and values. In P. Goldie (Ed.), The Oxford handbook of philosophy of emotion (pp. 475-500). Oxford University Press.

Nussbaum, M. (2001). Upheavals of thought: The intelligence of the emotions. Cambridge University Press.

Peacocke, C. (1984). Colour concepts and colour experience. Synthese, 58, 365-381.

Perler, D. (2011). Transformation der Gefühle. Fischer.

Pettit, P. (1990). The reality of rule-following. Mind, 99, 1-21.

Pettit, P. (1991). Realism and response-dependence. Mind, 100, 587-626.

Prinz, J. (2007). The emotional construction of morals. Oxford University Press.

Prinz, J., \& Nichols, S. (2010). Moral emotions. In J. M. Doris (Ed.), The Moral Psychology Research Group The moral psychology handbook (pp. 111-146). Oxford University Press.

Salmela, M. (2011). Can emotion be modelled on perception. Dialectica, 65(1), 1-29.

Schroeter, F. (2006). The limits of sentimentalism. Ethics, 116, 337-361.

Sher, G. (2001). But I could be wrong. Social Philosophy and Policy, 18, 64-78.

Shoemaker, D. (2017a). Response-dependent responsibility; or, a funny thing happened on the way to blame. Philosophical Review, 126, 481-527.

Shoemaker, D. (2017b). Cruel jokes and normative competence. Social Philosophy and Policy, 35, $173-195$.

Sinnott-Armstrong, W. (1991). Moral experience and justification. The Southern Journal of Philosophy, 29, 89-96. 
Sinnott-Armstrong, W., Liane, Y., \& Cushman, F. (2010). Moral intuitions. In: J. M. Doris (Ed.), The Moral Psychology Research Group, The moral psychology handbook (pp. 246-272). Oxford University Press.

Strawson, P. F. (1974). Freedom and resentment. In: P. F. Strawson (Ed.), Freedom and resentment (pp. 1-28). Methuen.

Szigeti, A. (2013). Emotions and heuristics. Ethical Theory and Moral Practice, 16, 845-862.

Szigeti, A. (2015). Sentimentalism and moral dilemmas. Dialectica, 69(1), 1-22.

Szigeti, A. (2021). The heuristics model of emotions and moderate rationalism. manuscript.

Tappolet, C. (2000). Émotions et valuers. Universitaires de France.

Teroni, F. (2007). Emotions and formal objects. Dialectica, 61(3), 395-415.

Vance, J. (2014). Emotion and the new epistemic challenge from cognitive penetrability. Philosophical Studies, 169, 257-283.

Wallace, J. R. (1994). Responsibility and the moral sentiments. Harvard University Press.

Wiggins, D. (1987). A sensible subjectivism. In D. Wiggins (Ed.), Needs, values, truth, 3rd Clarendon (pp. 185-214)

Publisher's Note Springer Nature remains neutral with regard to jurisdictional claims in published maps and institutional affiliations. 